\title{
Understanding Tree Health under Increasing Climate and Trade Challenges: Social System Considerations
}

\author{
Mariella Marzano ${ }^{1, *(1)}$ and Julie Urquhart ${ }^{2}$ (D) \\ 1 Forest Research, Northern Research Station, Roslin, Midlothian EH25 9SY, UK \\ 2 Countryside \& Community Research Institute, University of Gloucestershire, Francis Close Hall Campus, \\ Swindon Road, Cheltenham, Gloucestershire GL50 4AZ, UK; jurquhart1@glos.ac.uk \\ * Correspondence: mariella.marzano@forestresearch.gov.uk
}

Received: 10 September 2020; Accepted: 25 September 2020; Published: 28 September 2020

\begin{abstract}
Tree and forest health is increasingly influenced by climate change as well as growing globalisation and trade. Climate change enables species to colonise new environments, and species that previously were constrained by native predators are now able to flourish in these new environments with little or no resistance. Additionally, the growing trade in live plants and wood products results in the inadvertent movement of species (such as pests or fungi in soil) from far away areas of the globe. As a result, new forest and tree risks may occur with the potential for significant impacts on forest and tree health. However, managing these impacts through legislation and policy is a challenge, particularly in terms of balancing a predominant free trade policy alongside substantial biosecurity concerns. This Special Issue highlights the social system considerations around forest health: the ways in which specific legislative and policy systems, at the national, regional or local level, aim at regulating or managing increasing invasive species risks and outbreak events; the ways in which policy instruments, technologies or management practices can be developed to manage tree pests and pathogens; and the socioeconomic and cultural implications of pest or disease outbreaks. It illustrates the possibilities and limitations in specific socioeconomic and political systems to manage and limit the impacts of increasing challenges to forest health under climate change and globalisation.
\end{abstract}

Keywords: tree health; biosecurity; social science; pest; pathogen; governance; plant trade

\section{Introduction}

The social dimensions of tree and plant health (hereafter referred to as plant health) is a growing field of study contributing to the wealth of scientific analyses on the impacts and management of invasive pests and diseases. It is clear that the health of our trees, woods and forests face challenges from the immense changes brought on by climate change and worldwide trade and travel [1-4]. The speed and voracity of the global human health COVID-19 pandemic of 2020 is testament to how we are all interconnected and highlights the difficulties of managing invasive threats as they move through porous sociopolitical, physical and ecological borders. Tackling global infectious disease needs engagement and attention from everyone, including governments, businesses and the general population. While plant pests and diseases may not have a direct human health impact (although some do, such as oak processionary moth), these pests and pathogens damage and/or alter the natural world, affecting human interests and attachments that are aesthetic, cultural and economic, alongside the ecological impacts on habitats, biodiversity and ecosystem functions. As the exponential growth of pests and diseases continues, the inclusion of a broader range of actors in discussions and deliberations around pathways by which plant pests and diseases spread and establish, and how these are managed, is urgently needed. However, the addition of more diverse voices in debating management actions 
and broader biosecurity policy is not without its complexities, given the inevitable need for tradeoffs and compromise in decision-making. This is where social science is needed.

This Special Issue coincides with the United Nation's (UN) International Year of Plant Health (IYPH) in 2020, providing an opportunity to raise awareness globally on how protecting plant health can help in addressing the challenges of ending hunger and poverty, protecting the environment and boosting economic development. The Special Issue, consisting of ten diverse papers, highlights the wide range of social studies that can contribute to our greater understanding of plant health, focusing on trees and woodland. It also emphasises the social system considerations around tree health: the ways in which specific legislative and policy systems, at the national, regional or local level, aim at regulating or managing increasing invasive species risks and outbreak events; the ways in which policy instruments, technologies or management practices can be developed to manage tree pests and pathogens; and the socioeconomic and cultural implications of pest or disease outbreaks.

In the first paper, Holmes et al. [5] note that biotic disturbances leading to large-scale tree losses and consequent loss of ecosystem services are linked to decreases in human life satisfaction. In their study of the recent mountain pine beetle (Dendroctonus ponderosae) (MPB) outbreak in the western United States, the authors found that extensive forest mortality events can result in substantial losses in subjective measures of wellbeing. They also found that such reductions in forest quality resulted in a reduction in property values in affected areas. Li et al. [6] made similar observations in the context of the negative impact of tree damage due to emerald ash borer (Agrilus planipennis) (EAB) on home values in urban neighbourhoods with a high ash component in Milwaukee, Wisconsin, USA. Indeed, several of the papers from the UK and USA focus on ash, reflecting wide-ranging concerns around the loss of this prevalent and often culturally important species. Emerald ash borer in the USA and ash dieback (Hymenoscyphus fraxineus) in the UK have had devastating consequences for people and places where it has occurred and it is still spreading. In the USA, Li et al. [6] emphasise that tree boring pests such as EAB can severely impact social and economic values. For example, extensive tree mortality due to $\mathrm{EAB}$ can lead to a significant reduction in the ecosystem services those trees provide such as shade, privacy, regulating water quality and visual aesthetics, and this loss will have a knock-on effect on property values [6]. Tree and plant health in urban settings is an under-researched area even though impacts on ecosystem services are likely to be greatest. In the UK, the large numbers and widespread distribution of ash trees outside of traditional woodlands such as in hedgerows and parks, but also fields, streets, gardens, roads and rail networks, highlight the difficulties of managing the impacts of pests and pathogens on trees across the landscape. Ambrose-Oji et al. [7] 2019 acknowledge the challenges of a landscape approach to ash dieback where many trees are affected over a wide area, emphasising that decision-making is fraught with difficulties when faced with numerous, fragmented land use and a mix of public and private ownership. This can be complicated further by local governance structures [7]. In the UK, for example, decisions about ash dieback at the local authority level can take place separately across multiple departments, depending on where the ash trees are located. A concern raised both by Ambrose-Oji et al. [7] and Li et al. [6] in circumstances where the likelihood of pest or pathogen impacts are high, but there are uncertainties about what to do is that trees can be seen as a threat or liability rather than an asset. Thus, understanding knowledge (e.g., about pests and diseases), values (e.g., associated with trees) and risk perceptions are likely to be important and key areas where the social sciences can contribute.

Ambrose-Oji et al. [7] also highlight that pest and disease management can be demanding for local authorities in the UK, requiring processing skills to deal with multiple sources of competing information, some of which can be new or uncertain requiring a level of interpretation. In these contexts, decision-making is likely to be reactive and based on experience. Wall et al. [8] provide another perspective on forest governance with the example of local land managers in Turkey who grow chestnut (Castinea sativa) facing opposition to their practices on state-owned land [8]. Investigations by the authors found that traditional land management practices positively contributed to healthy chestnut populations, but these practices are treated with suspicion by state authorities. As an important tree 
species in Turkey, chestnut is part of the government's conservation programme, which includes limiting current livelihood practices in the forests by local people. Differing risk perceptions have led forest authorities to believe that human activity in the forests is negative instead of considering the positive roles that people play in maintaining forest health as part of their livelihood practices. Risk perceptions around practices such as grafting to increase commercial chestnut production have, according to Wall et al. [8], impeded the growth of multipurpose community forest initiatives. They call for greater inclusion of local knowledge in forest management thinking and emphasise the contribution of traditional practice to creating resilient forests. Urquhart et al. [9] also explore differences in risk perceptions, this time between publics and local stakeholders, emphasising the lack of empirical evidence on the pest and disease risks that people living, working or recreating in outbreak areas are concerned about [9]. Without this evidence, assessing likely public concern to a specific hazard or risk is challenging, particularly as the perceptions and responses of different stakeholder groups to risks can vary from expert views or even what is represented in the media. With a focus on ash dieback in the UK, the authors identified five key narratives that influence how people responded to the ash dieback outbreak. The first of these, "calls for better biosecurity" is concerned with the need to prevent future outbreaks, while the second, "resilient nature and technoscientific solutions" believes nature is resilient and, with help from science, will cope. The narrative "fatalistic" is pessimistic about future tree health believing that nothing can be done to prevent future outbreaks, while conversely "proactive citizens" argue that individuals can make a difference and play their part in preventing future outbreaks. One narrative, "disinterested", represents those who are not concerned or interested in tree health. These narratives are informed by underlying values and beliefs about nature and can usefully inform managers about likely reactions to pest and disease incursions, as well as what actions will be socially acceptable. Urquhart et al. [9] highlight that understanding risk perceptions is also essential for targeted risk communication strategies and homogenous communication is unlikely to change attitudes or behaviours.

Risk perception is also a strong theme in Marzano et al.'s [10] paper that also focusses on ash but this time in relation to the potential threat posed to Europe by EAB. The impacts of EAB on European ash trees that are also affected by ash dieback are relatively unknown and while contingency plans are being prepared at national levels, the authors argue that now is the time to gather evidence on the social dimensions of EAB impacts. In this case, the social dimensions include exploring perceptions of risks and benefits and how these may translate into the social acceptability (or not) of management measures such a chemical use, felling of ash trees and biological control. These data are not yet available in Europe, and so the authors look to the USA where this pest has been prolific, widespread and highly destructive since its introduction, particularly in residential areas of towns and cities. Social research on EAB is sparse, but the authors suggest where evidence is needed. For example, chemical use in the natural environment is generally contentious, but there is a requirement to understand the values associated with ash in different environments and whether the benefits of chemicals may outweigh the perceived risks. For other management measures, the economic costs, effectiveness of different measures and biosecurity implications (e.g., replacing ash with other species or introducing biological control) will all contribute to social acceptability considerations. Like Urquhart et al., [9] the authors emphasise that risk communications around $\mathrm{EAB}$ should to be targeted but, more importantly, engagement needs to start early on as countries prepare for the arrival of EAB so there is higher awareness of the likely impacts and the roles that people can play in mitigating the spread of beetle. Here, it will also be important that risk perceptions will influence decision-making and behaviours, but these perceptions in turn are also influenced by environmental beliefs, values or worldviews.

In a second paper, Marzano et al. [11] explore a similar theme of values versus risk in relation to management of the non-native oak processionary moth (Thaumetopoea processionea) (OPM) in the UK [11]. The caterpillars can defoliate oak trees leaving them vulnerable to other threats, but they also pose a risk to human and animal health. As such, in the UK it is a notifiable pest which means that sightings must be reported and action must be taken once a statutory plant health notice is issued. 
Since its introduction into the UK, OPM is primarily found in the southeast of the country, in Greater London and some surrounding counties. The urban setting is important here as trees and greenspaces and the ecosystem services they provide are particularly important as recreational spaces for urban communities. In this context, there is a legitimate policy concern that the risks associated with OPM may negatively impact the future of oak trees in the urban landscape, such that land managers may be tempted to remove existing infested oak trees that potentially pose a risk to human health or simply refuse to plant new oak. Similar to Ambrose-Oji et al. [7] and Li et al., [6] there is a risk that the iconic oak tree may be seen as a liability. Marzano et al. [11] investigate how land managers assess the tradeoffs between the perceived risks of OPM, the management measures used to control the pest and the values associated with oak trees and the biodiversity they support. These tradeoffs are influenced by, for example, uncertainty over where OPM really is a public health issue, the risk of reputational damage from not managing OPM in case there is a human or animal health incident, to concern over the impacts of chemical control for OPM on oak biodiversity. The authors suggest that in contexts where there are multiple and varied stakeholders, site types, governance models and levels of risk, an approach is needed that provides land managers with the flexibility to make their own decisions on risk rather than having to implement statutory requirements. As Wall et al. [8] point out, there is some merit in trusting local land managers to make the right decisions about the trees they manage.

Holmes et al. [5] suggest that investigations into the linkages between tree health and human wellbeing can provide justifications for costly protection measures. Where costs of management appear to be prohibitive or where collective action is known to reduce the potential of spread, collaboration is essential. However, outside of traditional forest settings, it can be challenging to assess who has responsibility for surveillance, control or management of pest or pathogen incursions. White et al. [12] echo this concern suggesting the need for increased awareness of tree pests and diseases and the roles that state and nonstate actors can play through the development of stronger networks. The authors focus on surveillance and early detection, exploring the meanings behind border surveillance and how the "border" is conceived through a variety of lenses, be they geopolitical, conceptual or biophysical. They highlight that borders are not only fixed lines on a map, but represent a process through which power and control can be exerted, involving regulation (the formal border), activities and behaviours (border performance). Understanding how different actors interact to protect our trees and ecosystems at potential entry points or through various activities is important for future biosecurity. For many of the research participants they talked to, the border was difficult to define in terms of tree health, leading the authors to identify the "everywhere border" as a way of exploring how and where biosecurity threats should be targeted and managed. White et al. [12] also suggest that the "everywhere" border is also the "everyone" border, and that surveillance and early detection of pests and diseases is the responsibility of a wide range of actors and citizens from preborder control to onsite management and purchasing decisions.

Two papers focus on technologies to improve surveillance and control efforts-a mobile phone citizen science app and the use of UAVs (unmanned aerial vehicles) or drones. Here, the authors explore social acceptability issues around the development and use of these technologies in the wider environment. Grant et al. [13] provides insights into the codesign of a smart phone citizen science surveillance network in New Zealand. The authors argue that New Zealand's aspiration to involve the whole of the population in biosecurity surveillance is hampered by current systems that may struggle to handle an increased public response, but also that communities are not as engaged as they could be. Grant et al. [13] highlight that socio-technological innovations through codesign require deep thinking about how to transform existing systems of surveillance so that they are able to take into account the different ways in which new users may relate to technologies. To integrate new users into the design process demands courage, acknowledging the costs of change for those already embedded in the system and trust in a process that will likely lead to new ways of operating. Improving surveillance and control systems to make them democratic and fit for purpose requires societal acceptability. Ogilvie et al. [14] introduces the concept of social license to operate (SLO) in biosecurity when considering the use of 
UAVs as a tool for eradicating pest incursions in New Zealand's ports, airports and surrounding residential areas. A SLO involves obtaining informed consent of communities and stakeholders that are likely to be affected and is a process that is ongoing. The authors emphasise that surveillance tools may be technologically sound, but without societal support they will fail in their purpose. In relation to UAVs, there are issues around privacy, safety, ethics and increased visual and noise pollution from flying drones. To improve biosecurity in urban areas requires greater engagement with communities that are also typically hard-to-reach. Like Grant et al. [13], Ogilvie et al. [14] call for greater involvement and codesign of technologies suggesting that familiarity and trust will increase social acceptability. They promote the use of participatory codesign of new technologies-through the use of a visual tool-to incorporate social and cultural considerations and facilitate the inclusion of a broader range of views and expertise to inform technology design and use.

As the papers in this Special Issue highlight, trees and forests provide a wide range of ecosystem services and benefits to human wellbeing, livelihoods and cultural value. But these services are threatened by an increasing number of new tree pest and pathogen invasions caused by global trade and climate change. Interventions to reduce the risk of new introductions is challenging, involving negotiating complex trade pathways and economic imperatives that encourage more open borders to trade. Once pests or pathogens are established in a new environment, management to eradicate or contain them is also challenging, requiring the development of new technologies for detection and treatment, as well as tradeoffs in management approaches that are socially acceptable. Such solutions require a better understanding of social systems and we suggest including consideration of human-environment relationships between people and trees; the impacts of pests and diseases on these relationships, at the local, regional, national and international scale; and different sociopolitical, physical, economic and cultural contexts.

Author Contributions: Both authors contributed to the writing of this editorial. All authors have read and agreed to the published version of the manuscript.

Funding: This research received no external funding.

Conflicts of Interest: The authors declare no conflict of interest.

\section{References}

1. Linnakoski, R.; Kasanen, R.; Dounavi, A.; Forbes, K. Forest Health under Climate Change: Effects on Tree Resilience, and Pest and Pathogen Dynamics. Front. Plant Sci. 2019. [CrossRef]

2. Potter, C.; Urquhart, J. Tree disease and pest epidemics in the Anthropocene: A review of the drivers, impacts and policy responses in the UK. For. Policy Econ. 2017, 79, 61-68. [CrossRef]

3. Ramsfield, T.; Bentz, B.; Faccoli, M.; Jactel, H.; Brockerhoff, E.G. Forest health in a changing world: Effects of globalization and climate change on forest insect and pathogen impacts. Forestry 2016, 89, 245-252. [CrossRef]

4. Urquhart, J.; Marzano, M.; Potter, C. Introducing the human dimensions of forest and tree health. In The Human Dimensions of Forest and Tree Health; Palgrave Macmillan: London, UK, 2018; pp. 1-20. [CrossRef]

5. Holmes, T.P.; Koch, F. Bark beetle epidemics, life satisfaction, and economic well-being. Forests 2019, 10, 696.

6. Li, X.; Holmes, T.P.; Boyle, K.J.; Crocker, E.V.; Nelson, C.D. Li Hedonic analysis of forest pest invasion: The case of Emerald Ash Borer. Forests 2019, 10, 820. [CrossRef]

7. Ambrose-Oji, B.; Stokes, J.; Jones, G.; Oji, A. When the Bough Breaks: How Do Local Authorities in the UK Assess Risk and Prepare a Response to Ash Dieback? Forests 2019, 10, 886. [CrossRef]

8. Wall, J.; Köse, C.; Köse, N.; Okan, T.; Aksoy, E.B.; Jarvis, D.I.; Allred, S.B. The role of traditional livelihood practices and local ethnobotanical knowledge in mitigating chestnut disease and pest severity in turkey. Forests 2019, 10, 571. [CrossRef]

9. Urquhart, J.; Potter, C.; Barnett, J.; Fellenor, J.; Mumford, J.; Quine, C.P. Using Q methodology to explore risk perception and public concern about tree pests and diseases: The case of ash dieback. Forests 2019, 10, 761.

10. Marzano, M.; Hall, C.; Dandy, N.; Fisher, C.L.; Diss-Torrance, A.; Haight, R.G. Lessons from the frontline: Exploring how stakeholders may respond to emerald ash borer management in Europe. Forests 2020, 11, 617. [CrossRef] 
11. Marzano, M.; Ambrose-Oji, B.; Hall, C.; Moseley, D. Pests in the city: Managing public health risks and social values in response to oak processionary moth (thaumetopoea processionea) in the United Kingdom. Forests 2020, 11, 199. [CrossRef]

12. White, R.M.; Marzano, M.; Leahy, S.; Jones, G. Are we defending the indefensible? Reflecting on policy and practice around 'the border' in plant biosecurity for tree health. Forests 2019, 10, 716. [CrossRef]

13. Grant, A.; Pawson, S.M.; Marzano, M. Emerging Stakeholder relations in participatory ICT design: Renegotiating the boundaries of sociotechnical innovation in forest biosecurity surveillance. Forests 2019, 10, 836. [CrossRef]

14. Ogilvie, S.; McCarthy, A.; Allen, W.; Grant, A.; Mark-Shadbolt, M.; Pawson, S.M.; Richardson, B.; Strand, T.; Langer, E.; Marzano, M. Unmanned aerial vehicles and biosecurity: Enabling participatory-design to help address social licence to operate issues. Forests 2019, 10, 695. [CrossRef]

C 2020 by the authors. Licensee MDPI, Basel, Switzerland. This article is an open access article distributed under the terms and conditions of the Creative Commons Attribution (CC BY) license (http://creativecommons.org/licenses/by/4.0/). 